\title{
ÉLITES ECLESIÁSTICAS Y SOCIEDAD EN EL SIGLO XVI: LA EXTRACCIÓN SOCIAL DE LOS CAPITULARES COMPOSTELANOS
}

\author{
Arturo IGLESIAS ORTEGA \\ Universidad de Santiago de Compostela
}

\begin{abstract}
RESUMEN: Partiendo del análisis sociológico de los 492 individuos que formaron parte del cabildo catedralicio de Santiago de Compostela a lo largo del siglo XVI, queremos demostrar que este se nutría fundamentalmente de las élites sociales, tanto locales como castellanas, en un momento en que la limpieza de sangre, nacida para impedir el acceso de las minorías conversas a las instituciones de honor, se convierte en un instrumento para consolidar la denominada cultura de élites.
\end{abstract}

PALABRAS CLAVE: análisis sociológico, cabildo catedralicio, cultura de élites, élites sociales, extracción social, limpieza de sangre, siglo XVI.

ABSTRACT: From the sociological analysis of the 492 individuals who were part of the cathedral chapter of Santiago de Compostela along the XVI century, I want to show that this is fed mainly from the social elites, both local and Castilian, in a time when purity of blood, born to prevent access of converts minorities to honor institutions, becomes an instrument to consolidate the so-called high culture.

KEYWORDS: cathedral chapter, high culture, purity of blood, social elites, social origin, sociological analysis, XVI century.

\section{CLASIFICACIÓN SOCIOECONÓMICA}

Los miembros de un cabildo catedralicio formaban parte de una élite por el simple hecho de pertenecer al mismo. Esa élite se nutría de individuos que en un alto porcentaje tenían una formación aceptable y que, en algunos casos, constituían un grupo académicamente selecto ${ }^{2}$. Otros estudios demuestran que sus ingresos y

${ }^{1}$ Recibido el 4 de julio de 2011. Aceptado en el Consejo de 8 de noviembre de 2011.

2 Véase, por ejemplo, P. C. QuintANA ANDRÉs (2004). 'Finis Gloriae Mundi'. Ideología y sociedad en Canarias. Los prebendados del cabildo Catedral durante el Antiguo Régimen (14831820). Gran Canaria: Gobierno de Canarias, Ayuntamiento de Agüimes, Centro de la Cultura Popular Canaria, p. 111; J. M. LÓPEZ ANDRÉS (1999). «Real patronato eclesiástico y presentación beneficial. La actuación de la Corona de Castilla en la diócesis de Almería». En CorTÉs PeÑA, A. L., LóPEZGuAdAlupe MuÑoz, M. L. y LaRA RAmos, A. (eds.). Iglesia y sociedad en el reino de Granada (ss. XVI-XVIII). Granada: Universidad de Granada, p. 119; P. FATJó GóMEZ (1999). «La formación 
nivel de vida eran elevados según su categoria capitular, como corresponde a una élite económica ${ }^{3}$. Se trata ahora de demostrar que también se componía de una élite social. Para determinar de qué ámbito socioeconómico procedían los casi 500 capitulares compostelanos del siglo XVI hemos tratado de reconstruir su genealogía e historia familiar, centrándonos sobre todo en la figura paterna, pues era a través del varón como se trasmitía la nobleza de sangre, la hidalguía, y, en general, en una sociedad de carácter marcadamente masculino, el linaje se iba sucediendo de padres a hijos. Cuando la información sobre el padre o el abuelo paterno no fue suficiente o, como ocurre en muchos casos, no se encontró información alguna, recurrimos a la de otros parientes, entre ellos los maternos, partiendo de la base de que las familias de un mismo rango socioprofesional tienden a relacionarse entre ellas, de igual modo que se producen solidaridades entre los miembros de un mismo grupo. Para ello hemos contado con la información proveniente de distintas fuentes, fundamentalmente expedientes de limpieza de sangre, testamentos, dotes, partijas y cualquier otra escritura notarial que diese noticia de su familia, así como obras genealógicas y todo tipo de publicaciones científicas ${ }^{4}$. Además de tener en cuenta los vínculos familiares y las relaciones horizontales, se han valorado de manera complementaria, cuando ha sido necesario, otros indicadores socioeconómicos de su pertenencia a las élites, como la existencia de vínculos o mayorazgos familiares, muchas veces fundados o acrecentados por los propios capitulares, el número de sirvientes de cada capitular, la cuantía de las dotes aportadas por los mismos o la tipología y cuantía de sus patrimonios, información que hemos podido extractar principalmente de un buen número de testamentarías.

A tenor de los datos obtenidos, hemos optado por una clasificación en la que se distinguen tres grandes grupos socioeconómicos: las clases privilegiadas, las élites

cultural del clero en la Cataluña del XVII: la clerecía catedralicia de Barcelona». En MARTínEZ Shaw, C. (ed.). Historia moderna, historia en construcción. Sociedad, Política e Instituciones. Lleida: Editorial Milenio, vol. II, p. 105; A. IgLeSIAS CASTELAO (1996). «Análisis sociológico del cabildo compostelano a través de los expedientes de limpieza de sangre». Compostellanum, XLI, p. 445; O. Rey CastelaO. (1990): «El alto clero gallego en tiempos de Carlos III». En Coloquio internacional Carlos III y su siglo. Madrid: Universidad Complutense, t. II, pp. 588-589; M. J. LoP OTín (2003). El cabildo catedralicio de Toledo en el siglo XV. Aspectos institucionales y sociológicos. Madrid: Fundación Ramón Areces, p. 419.

${ }^{3}$ Véase, A. Morgado García (2002). «Vida de canónigo. Percepción, origen y status de vida del alto clero durante el Antiguo Régimen». En ARAnda Pérez, F. J. (coord.). Sociedad y élites eclesiásticas en la España moderna. Cuenca: Universidad de Castilla-La Mancha, pp. 87-91.

${ }^{4}$ Debemos destacar, en este sentido, la documentación conservada en el Archivo de la Catedral de Santiago (ACS) y en el Arquivo Histórico Universitario de Santiago (AHUS). 
urbanas y las élites rurales ${ }^{5}$. Dentro de las clases privilegiadas distinguimos los dos estamentos privilegiados, nobleza y clero. Desde hace mucho tiempo sabemos que la rígida visión de la sociedad estamental tripartita (nobleza, clero, estado llano) no respondía a la realidad social en época moderna, mucho más compleja, en la que la la creciente movilidad social intra-estamental e inter-estamental, se unía la constatación de situaciones y comportamientos teóricamente más propios de un grupo social en individuos pertenecientes a otro ${ }^{6}$. En este sentido, la expresión clases privilegiadas puede chocar con situaciones excepcionales como, por ejemplo, la de las oligarquías municipales que logran la exención de ciertos tributos $^{7}$. En el otro sentido, hemos considerado dentro de aquellas a los capitulares hijos de nobles y clérigos, independientemente de que participasen de características de otros grupos: por ejemplo, los hijos de nobles que han ocupado además cargos concejiles, formando parte de las oligarquías urbanas, y los que han practicado actividades impropias de su nobleza (mercantiles, mecánicas o viles), o los hijos de clérigos de distinta procedencia social. En lo básico, hemos seguido la jerarquía nobiliaria propuesta en su día por Domínguez Ortiz ${ }^{8}$, obviando la categoría superior (grandes de España), de la que no hemos hallado ningún caso, y la inferior (situaciones prenobiliarias o de dudosa nobleza) por ser bastante difícil averiguar el origen de la nobleza de muchos de los capitulares, e introduciendo la de los señores de casas solariegas entre la hidalguía y la nobleza media, representada por los caballeros $^{9}$ : nobleza titulada, señores jurisdiccionales, caballeros de hábito y comendadores, caballeros, señores de casa solariega e hidalguía (una última categoría sería la representada por aquellos hijos de nobles sin mayor precisión). En cuanto al clero, lo hemos clasificado en prelados, capitulares, presbíteros (sólo cuando no están dentro de las anteriores categorías) y clérigos sin especificar (aquí entrarían los hijos de clérigos de órdenes menores, subdiáconos y diáconos).

\footnotetext{
${ }^{5}$ Una panorámica general en Tabla $\mathrm{n}^{\circ} 2$. Para conocer los datos al completo con todos los grupos sociales, véase Tabla $\mathrm{n}^{\circ} 4$.

${ }^{6}$ Véase lo dicho en A. Domínguez OrTiz (1973). Las clases privilegiadas en la España del Antiguo Régimen. Madrid: Istmo, pp. 9-15.

7 J. M. CARRETERo ZAMORA (1998). «Las oligarquías locales y los mecanismos de exención del servicio de Cortes en la época de Carlos V». Espacio, Tiempo y Forma. Serie IV. Historia Moderna, 11, pp. 11-37.

${ }^{8}$ A. Domínguez Ortiz (1973). Op. cit., p. 52.

${ }^{9}$ Véase a este respecto lo dicho en E. SORIA MESA (2007). La nobleza en la España moderna. Cambio y continuidad. Madrid: Marcial Pons, pp. 37-74.
} 
Por lo que toca a los grupos urbanos, hemos englobado a las élites de poder político, social y económico usando la expresión élites urbanas, puesto que a las denominadas oligarquías municipales, que definen esencialmente a los grupos dirigentes de los concejos urbanos (es decir, al poder político) ${ }^{10}$, se suman individuos que participan del poder económico por sus profesiones (comerciantes, artesanos) o que forman parte de las élites intelectuales (profesiones liberales como los médicos). En cualquier caso, debemos considerar dicha expresión con cautela por dos motivos: en primer lugar, porque hay un buen número de capitulares, de cuyos padres no hemos podido precisar su categoría profesional, si bien hemos deducido que estaría situada dentro de uno de esos grupos de poder urbano; y, en segundo lugar, porque la pertenencia a una de esas profesiones o categorías socioprofesionales no es garantía de pertenencia a las élites urbanas ${ }^{11}$. El hecho de que no hayamos constatado dentro de estos grupos urbanos a ningún elemento de las más bajas capas sociales nos lleva a descartar la expresión clases urbanas sin más, pero, dado que es corriente equiparar a las élites con las oligarquías y patriciados urbanos, quizás fuese más correcto hablar de "grupos urbanos de poder". Dicho esto, hemos optado por distinguir dentro de estas clases urbanas a una burguesía administrativa (los regidores, letrados y cargos concejiles, es decir, las tradicionalmente denominadas oligarquías urbanas, junto con otras profesiones liberales), a una burguesía económica (comerciantes y artesanos) y a un conjunto sin especificar, por no poder situarlo con seguridad ni en uno ni en otro subgrupo.

El tercer grupo en discordia lo hemos denominado élites rurales, que agrupa a los que la documentación llama labradores y a un conjunto sin especificar de vecinos de pueblos y aldeas con propiedades agrícolas y/o ganaderas. Quizás podríamos considerarlos a todos como parte de un mismo grupo, de las oligarquías

${ }^{10}$ Para conocer un estado de la investigación sobre oligarquías municipales pueden verse los trabajos de E. SORIA MESA (2000). «Los estudios sobre las oligarquías municipales en la Castilla moderna. Un balance en claroscuro», Manuscrits, 18, pp. 185-197; y de M. LÓPEZ DíAZ (2004). "Poder municipal y oligarquías urbanas en la Galicia moderna. Un balance y algunas reflexiones". Studia Storica. Historia Moderna, 26, pp. 321-348.

${ }^{11}$ Aunque para un período posterior (mediados del siglo XVIII), el profesor Eiras Roel clasifica a las clases urbanas en élites urbanas, clases medias urbanas, artesanado urbano y el resto (indiferenciados, diversos, pobres y campesinado rururbano). Empleando una serie de variables que definen a las élites urbanas compostelanas, demuestra que la sola pertenencia a un estamento privilegiado, el desempeño de un cargo público o el ejercicio de una profesión no garantizan que lleguen a alcanzar los niveles de las élites, pudiendo encontrar a mercaderes, boticarios y médicos dentro de ellas, pero también a hidalgos, clérigos y letrados fuera de ellas (A. EIRAS RoEL (1982). «Las élites urbanas de una ciudad tradicional: Santiago de Compostela a mediados del siglo XVIII». En Actas del II Coloquio de Metodología Histórica Aplicada. La documentación notarial y la historia. Santiago: Universidad de Santiago, vol. I, pp. 117-139). 
rurales, pero, por un lado, el término labrador es demasiado difuso como para hacer esta generalización ${ }^{12}$, y, por otro, dentro de las élites rurales habría que incluir también a los grandes propietarios agropecuarios, que en gran parte estarían situados en los otros dos grupos, sobre todo en el de los privilegiados.

Tabla no 1. Conocimiento de la extracción social de los capitulares

\begin{tabular}{crrrrrrrrrr}
\hline \multirow{2}{*}{ G. Socioec. } & \multicolumn{2}{c}{ Dignidades } & \multicolumn{2}{c}{ Canónigos } & \multicolumn{2}{c}{ C. Oficio } & \multicolumn{2}{c}{ Racioneros } & \multicolumn{2}{c}{ Total } \\
\cline { 2 - 12 } & $n^{o}$ & $\%$ & $n^{o}$ & $\%$ & $n^{o}$ & $\%$ & $n^{o}$ & $\%$ & $n^{o}$ & $\%$ \\
\hline Conocido & 77 & 74,04 & 185 & 71,71 & 18 & 72 & 53 & 50,48 & 333 & 67,68 \\
Se ignora & 27 & 25,96 & 73 & 28,29 & 7 & 28 & 52 & 49,52 & 159 & 32,32 \\
\hline Total & 104 & 100 & 258 & 100 & 25 & 100 & 105 & 100 & 492 & 100 \\
\hline
\end{tabular}

Tabla no 2. Extracción social de los capitulares

\begin{tabular}{|c|c|c|c|c|c|c|c|c|c|c|}
\hline \multirow{2}{*}{ G. Socioec. } & \multicolumn{2}{|c|}{ Dignidades } & \multicolumn{2}{|c|}{ Canónigos } & \multicolumn{2}{|c|}{ C. Oficio } & \multicolumn{2}{|c|}{ Racioneros } & \multicolumn{2}{|c|}{ Total } \\
\hline & $n^{o}$ & $\%$ & $n^{o}$ & $\%$ & $n^{o}$ & $\%$ & $n^{o}$ & $\%$ & $n^{o}$ & $\%$ \\
\hline A & 57 & 74,03 & 107 & 57,84 & 7 & 38,89 & 19 & 35,85 & 190 & 57,06 \\
\hline B & 50 & 87,72 & 75 & 70,09 & 6 & 85,71 & 12 & 63,16 & 143 & 75,26 \\
\hline $\mathrm{C}$ & 7 & 12,28 & 32 & 29,91 & 1 & 14,29 & 7 & 36,84 & 47 & 24,74 \\
\hline $\mathrm{D}$ & 17 & 22,08 & 69 & 37,30 & 8 & 44,44 & 27 & 50,94 & 121 & 36,34 \\
\hline $\mathrm{E}$ & 9 & 52,94 & 15 & 21,74 & 4 & 50 & 6 & 22,22 & 34 & 28,10 \\
\hline $\mathrm{F}$ & 6 & 35,29 & 38 & 55,07 & 3 & 37,50 & 7 & 25,93 & 54 & 44,63 \\
\hline G & 2 & 11,76 & 16 & 23,19 & 1 & 12,50 & 14 & 51,85 & 33 & 27,27 \\
\hline $\mathrm{H}$ & 3 & 3,90 & 9 & 4,86 & 3 & 16,67 & 7 & 13,21 & 22 & 6,61 \\
\hline I & 3 & 100 & 8 & 88,89 & 0 & 0 & 5 & 71,43 & 16 & 72,73 \\
\hline $\mathrm{J}$ & 0 & 0 & 1 & 11,11 & 3 & 100 & 2 & 28,57 & 6 & 37,50 \\
\hline Total & 77 & 100 & 185 & 100 & 18 & 100 & 53 & 100 & 333 & 100 \\
\hline
\end{tabular}

A, Clases privilegiadas; B, Nobles; $C$, Clero; D, Élites urbanas; E, Sin especificar; $F$, Burguesía administrativa; $G$, Burguesía económica; H, Élites rurales; I, Sin especificar; J, Labradores

De los 492 capitulares analizados hemos podido identificar o deducir la procedencia social de las dos terceras partes de los casos (Tabla n $\left.{ }^{\circ} 1\right)$. Según el tipo de prebenda, este porcentaje se sitúa en torno al $72 \%$ para los grupos capitulares superiores y tan sólo en el 50\% para los racioneros, de quienes se dispone, en general, de mucha menos información. Es, en todo caso, una muestra amplísima y

12 Frente a definiciones menos elásticas como las de Domínguez Ortiz (campesino propietario acomodado) o Salomon (campesino que poseía uno o más tiros de animales de labranza), Vassberg, indicando la dificultad de distinguir a un campesino rico de uno pobre en el siglo XVI, define al labrador como a un agricultor indepediente (D. E. VASSBERG (1986). Tierra y sociedad en Castilla. Señores, "poderosos” y campesinos en la España del siglo XVI. Barcelona: Crítica, pp. 187-193). 
altamente significativa para el número de capitulares tratado y para las fuentes de las que se dispone.

Centrándonos únicamente en los casos conocidos (Tabla $\mathrm{n}^{\circ} 2$ ), podemos destacar, en primer lugar, la preponderancia de los grupos privilegiados en la extracción social de los capitulares compostelanos $(57,06 \%)$. Dentro de estos, la nobleza es el grupo mayoritario con un $42,94 \%$, porcentaje ampliable al $48,65 \%$ si consideramos a los hijos de clérigos nobles. La vinculación entre los estamentos privilegiados, especialmente la nobleza aristocrática, y las élites eclesiásticas es un tema conocido y estudiado desde hace bastantes años. Los motivos de la inclusión en las filas capitulares de miembros de la nobleza se pueden resumir, por una parte, en el deseo por parte de determinados linajes de ver reflejado su predominio social en el control de los puestos más selectos de la Iglesia, lo que, a su vez, redundaría en el prestigio social de su familia; por otra, en la búsqueda de una salida económica notablemente apreciable a los miembros segundones de muchas familias nobles, marginados por la preferencia de los primogénitos y de los herederos de los mayorazgos, y en un contexto económico muchas veces poco favorable, que aconsejaba la vía eclesial para no disminuir el patrimonio familiar y su posición económica y social; y finalmente en el desarrollo de una estrategia de amortización socioeconómica, que permitía reducir los costes de reproducción social y aumentar los niveles de influencia y de riqueza del linaje en un proceso de inversión recíproca: por un lado, el sufragio de los gastos para obtener la prebenda del capitular por parte de su familia; por otro, la creación o incremento del mayorazgo familiar, la dotación de parientes o la reversión del patrimonio invertido en el capitular e incrementado por este mediante sus legados testamentarios.

Son escasos los estudios cuantitativos sobre la extracción social de los capitulares y, en concreto, sobre el número de nobles en los cabildos catedralicios del período inmediatamente anterior al reformismo borbónico, representado en el Concordato de 1753, y mucho menos del siglo XVI ${ }^{13}$. La mayor parte de los estudios españoles sobre cabildos se centran en subrayar la importancia del componente nobiliario, estudiando algunos de sus linajes o dando ejemplos individualizados ${ }^{14}$, o de analizar la relación del cabildo y la nobleza local ${ }^{15}$. Una de

13 Por citar una obra clásica, en los cabildos más importantes de la Guyena francesa en época moderna la nobleza podía alcanzar entre una cuarta y tercera parte de sus efectivos capitulares (P. LOUPÈs (1985). Chapitres \& chanoines de Guyenne aux XVII et XVIII ${ }^{e}$ siècles. Paris: Ecole des Hautes Etudes en Sciences Sociales, p. 237).

${ }^{14}$ Véase, por ejemplo, sobre el capítulo toledano en el XVII lo dicho por R. SÁNCHEZ GonZÁLEZ (2000). Iglesia y sociedad en la Castilla moderna. El cabildo catedralicio de la Sede Primada (siglo XVII). Cuenca: Universidad de Castilla-La Mancha, pp. 31-32. Hay ejemplos de cabildos totalmente 
las excepciones es la investigación de Pedro Fatjó sobre el cabildo de Barcelona en el siglo XVII, que arroja un porcentaje del 62,26\% de capitulares de origen nobiliario (nobles, doncells, ciudadanos honrados) ${ }^{16}$. El caso cordobés puede ser un modelo comparable para la Corona de Castilla, si bien sólo se han estudiado los capitulares de los que se conserva expediente de limpieza de sangre de los siglos XVII y XVIII ${ }^{17}$. El trabajo de Vázquez Lesmes arroja como resultado un $69 \%$ de individuos de origen noble, porcentaje sensiblemente superior al caso compostelano (s. XVI) y muy similar al barcelonés (s. XVII), pero en total consonancia con los que ofrecen las informaciones de limpieza de sangre de la catedral compostelana para los mismos períodos (un 60,98\% en el siglo XVII; un $75,52 \%$ en el período 1600-1752), que vienen a demostrar un proceso de ennoblecimiento en el cabildo de Santiago ${ }^{18}$. El académico cordobés distribuye a los capitulares nobles en tres grupos: grandes (2,57\%), títulos, señoríos y órdenes militares $(28,30 \%)$ e hijosdalgo $(69,13 \%)$. En nuestro caso, dejando de lado a casi un $15 \%$ de nobles sin mayor especificación, la distribución sería la siguiente: grandes $(0,82 \%)$, títulos, señoríos y órdenes militares $(21,31 \%)$ e hijosdalgo $(77,87 \%)^{19}$. En este último grupo hemos incluido a los señores de casa solariega, que hay quien sitúa dentro de la baja nobleza junto al resto de los hidalgos, y a los caballeros hijosdalgo, que se pueden situar en el nivel medio de la nobleza, si bien se han detectado categorías prenobiliarias entre estos últimos. En cualquier caso, ambas categorías comparten la hidalguía con la gran masa de hidalgos y, sobre todo en el caso de los segundos, no son fácilmente identificables a través de la documentación, de ahí que su número sea poco significativo (6 casos reconocidos).

aristocráticos, como el de Girona, pero se suelen dar en época medieval (J. Molina FIGUERAS (2007). «De genere militari ex utroque parente. La nobleza eclesiástica y los inicios de la catedral gótica de Gerona». Anuario de Estudios Medievales, 37/1, pp. 741-746 y 748-764). Aún en época moderna el cabildo gerundense se comportaba como tal y tenía muchos caballeros feudatarios (A. DomínGUEZ ORTIZ, A (1973). Op. cit., p. 240).

${ }^{15}$ R. SÁNCHEZ GonZÁleZ (2000). Op. cit., pp. 128-138; R. VAZQUEZ LESMES (1987). Córdoba y su cabildo catedralicio en la Modernidad. Córdoba: Publicaciones de la Caja de Ahorros y Monte de Piedad de Córdoba, pp. 422-443.

${ }^{16}$ Cálculo elaborado a partir de los datos ofrecidos en P. FATJó GóMEZ (1993). «Aproximación a una élite institucional de la Catalunya moderna: los capitulares de la Seo de Barcelona en el siglo XVII». Pedralbes, 13-II, pp. 155-156.

${ }^{17}$ R. VÁZQUEZ LESMES (2008). «Participación y poder de la nobleza reflejados en la composición de un cabildo catedralicio. Córdoba, siglos XVII-XVIII». En Castellano Castellano, J. L. y López-Guadalupe Muñoz, M. L. (eds.). Homenaje a Don Antonio Domínguez Ortiz. Granada: Universidad de Granada y Junta de Andalucía, vol. II, pp. 813-829.

${ }^{18}$ Cálculo elaborado a partir de A. Iglesias CASTELAO (1996). Op. cit., pp. 437-438.

${ }^{19}$ Para conocer con detalle la cuantificación de las distintas categorías sociales en las que hemos dividido los grandes grupos socioeconómicos, véase Tabla $n^{\circ} 4$. 
Probablemente una gran parte de los que he clasificado como hidalgos perteneciesen a esa categoría de caballeros, que se define generalmente por su localización urbana y por formar parte de las oligarquías municipales. La diferente distribución porcentual de la nobleza capitular de uno y otro cabildo se puede relacionar con factores cronológicos y geográficos. En el primer caso, la explicación es tan simple como que el número de títulos y grandezas nobiliarias fue en el siglo XVI mucho menor que en los dos siglos posteriores, por lo que la probabilidad de que alguno de ellos introdujera a alguno de sus miembros en los capítulos catedralicios fue mucho mayor en el caso cordobés ${ }^{20}$. En el segundo caso, se solapan dos argumentos: el peso y calidad de la nobleza local y regional y la procedencia geográfica de los capitulares nobles. Es conocido el control del municipio cordobés por parte de la nobleza, especialmente en el período bajomedieval $^{21}$, y no sólo de manera directa, sino a través de sus clientelas ${ }^{22}$. A finales del siglo XV, el genealogista Hernán Mexía consideraba a Córdoba como uno de los cuatro lugares solariegos de la nación ${ }^{23}$. Por otra parte, hay una clara conexión entre la aristocracia cordobesa y su cabildo, especialmente la vinculada a la Casa de Córdoba ${ }^{24}$. Este dominio de la nobleza local se traduce en un 51,45\% frente al 48,55\% restante de la nobleza foránea entre las filas capitulares cordobesas $^{25}$.

Por su parte, Santiago de Compostela es una ciudad con un contingente nobiliario bastante reducido: según el recuento de 1591, los hidalgos representaban únicamente el $6,3 \%$ del vecindario ${ }^{26}$. Su poder, no obstante, fue notorio: durante la

${ }^{20}$ Sobre todos estos aspectos, véase lo dicho en E. SORIA MESA (2007). Op. cit., pp. 37-74; y A. DOMíNGUEZ ORTIZ (1973). Op. cit., pp. 52-57 y 71-85.

${ }^{21}$ Véase C. QuinTANILla RASO (1987). «El dominio de las ciudades por la nobleza. El caso de Córdoba en la segunda mitad del siglo XV». En la España medieval, 10, pp. 109-124.

${ }^{22}$ A. J. DíAz RodríGUEZ (2007). «De vasallos a señores. El servicio al señor como clave de acceso al cabildo catedralicio cordobés». En ANDÚJAR CASTILLO, F. y DíAZ LÓPEZ, J. P. (coords.). Los señoríos en la Andalucía moderna. El Marquesado de los Vélez. Almería: Instituto de Estudios Almerienses, pp. 655-667.

${ }^{23}$ Cit. A. DomíngueZ OrTIZ (1973). Op. cit., p. 28.

${ }^{24}$ R. VÁzquez Lesmes (2008). Op. cit., pp. 823-825. Según Vázquez Lesmes, "el término nobleza aplicado a los reinos de Andalucía se identifica plenamente con el de aristocracia, en contra de lo que ocurre en otras áreas geográficas españolas" (R. VÁZQUEZ LESMES (1987). Op. cit., p. 424).

${ }^{25}$ Cálculo elaborado a partir de los datos ofrecidos por R. VÁzQUEZ LESMES (2008). Op. cit., p. 821.

26 J. E. Gelabert GonZález (1982). Santiago y la Tierra de Santiago de 1500 a 1640 (Contribución a la historia económica y social de los territorios de la Corona de Castilla en los siglos XVI y XVII). Sada-A Coruña: Ediciós do Castro, p. 270. 
mayor parte de la centuria el regimiento de la ciudad estuvo jalonado de miembros de la baja nobleza e hidalguía local, los mismos que figuraban entre las fortunas locales más elevadas ${ }^{27}$. Sin embargo, de los capitulares nobles sólo un 9,79\% formaban parte de la nobleza local (considerando también a los naturales de la diócesis compostelana de los que no sabemos si nacieron en Santiago) y el 90,21\% restante era foráneo, principalmente de linajes castellanos. Aún contabilizando a todos los nacidos en Galicia, el contingente se reduce únicamente al 28,67\%. Por lo tanto, podemos afirmar que en el cabildo compostelano, aunque dio cabida a los linajes más egregios de la ciudad levítica (Acevedo, Galos-Abráldez, Ulloa) ${ }^{28}$, no estuvieron cuantitativamente más representados de lo que lo estaban entre la población de Santiago: si a los capitulares hijos de la nobleza local sumamos los hijos de clérigos nobles de origen local, el porcentaje respecto al total de capitulares de origen social conocido es del $6,31 \%$ (sería algo superior contabilizando a algunos de los gallegos que probablemente nacieron en Compostela). Por el otro lado, miembros de la alta nobleza, en un pequeñísimo porcentaje, y de la nobleza media y baja castellanas, en un grado superior, tuvieron en el cabildo compostelano un lugar donde colocar a sus segundones: la vía de acceso principal, común a todos los linajes foráneos, fue su vinculación con el arzobispo de turno (casi todos castellanos) o con los linajes castellanos ya establecidos en el cabildo, como más adelante veremos.

El porcentaje de hijos de clérigos alcanza al 14,11\% del total de casos cuya extracción social nos es conocida, conformando un contingente muy significativo. Su distribución interna es la siguiente: $61,70 \%$ para hijos de capitulares; $25,53 \%$

${ }^{27}$ Analizando el listado de regidores del período $1560-1599$, podemos calcular que cerca del $28 \%$ eran hidalgos, señores jurisdiccionales o ambas cosas (cálculo elaborado a partir de los datos ofrecidos en M. LÓPEZ DíAZ (1994). Gobierno y hacienda municipales. Los concejos de Santiago y Lugo en los siglos XVI y XVII. Lugo: Diputación Provincial de Lugo, pp. 291-292). Un porcentaje similar debía corresponder a la "vieja hidalguía santiaguesa" que estaba entre los vecinos con una fortuna igual o superior a los 1.000 ducados, según el padrón socioprofesional de 1588 (J. E. GelABERT GONZÁlEZ (1982). Op. cit., p. 272).

${ }^{28}$ He aquí algunos de sus miembros: del linaje Acevedo, los canónigos Alonso de Acevedo, Juan de Acevedo, Nicolás de Acevedo, Fernando Pérez de Acevedo y Fernando de Acevedo (emparentados con los Fonseca, de origen castellano la mayoría, que dejarían algunos prebendados como el arcediano y futuro arzobispo Alonso de Fonseca III, el canónigo Alonso de Fonseca, el canónigo Fernán de Fonseca y el chantre Alonso de Acevedo y Fonseca); del linaje Galos-Abráldez, el canónigo Pedro Galos da Costa y el racionero Juan Abráldez Feijoo; del linaje Ulloa, el canónigo García Díaz de Mesía, el cardenal Gonzalo Ozores de Ulloa, el juez Juan Rodríguez de Ulloa, el arcediano Lope Sánchez de Ulloa "el Viejo", el canónigo Lope Sánchez de Ulloa de la Fuente do Sequelo, el canónigo Lope Sánchez de Ulloa y Mesía, los canónigos Gonzalo de Ulloa, Rodrigo de Ulloa y Sancho de Ulloa. 
para hijos de presbíteros; 10,64\% para hijos de clérigos en general o sin presbiterado; y 2,13\% para hijos de prelados. Un buen número de ellos procede de miembros del capítulo compostelano (incluyendo al arzobispo de Santiago, que era dignidad del cabildo y disfrutaba de una prebenda) o de clérigos que antes o después de procrearlos formaron parte del mismo, como puede verse en la Tabla $\mathrm{n}^{\circ}$ $3^{29}$. Contando al hijo de un capellán rector de la parroquia compostelana de San Benito del Campo, serían 35 (74,47\%). La paternidad de algunos de los capitulares es un tema que trataremos em otro trabajoe con mayor detenimiento ${ }^{30}$. Ante esta mayoría de descendientes de prebendados compostelanos, es lógico que, dejando al margen aquellos de los que se ignora su procedencia geográfica, su origen sea mayoritariamente local $(65,12 \%)$ y gallego $(74,42 \%)$. La extracción social de esos padres clérigos es mayoritariamente noble $(60 \%)$, pero también hay una notable presencia de las élites urbanas $(33,33 \%)$, principalmente de las oligarquías municipales, y una mínima representación de las élites rurales $(6,67 \%)$, reproduciendo, así, el mismo modelo de distribución social de todo el conjunto capitular.

De acuerdo con la Tabla $\mathrm{n}^{\circ}$ 2, poco más de un $36 \%$ de los capitulares compostelanos formaban parte de las élites urbanas. No obstante, este porcentaje se incrementa notablemente $(46,55 \%)$ si consideramos a los hijos de clérigos adscritos a este grupo socioeconómico (10 individuos, como mínimo) y a los hijos de nobles que formaban parte de las oligarquías urbanas (24 individuos, al menos). El término "élites urbanas" esconde realidades muy diferentes. Un 16,22\% de los capitulares, como mínimo, formaría parte de la burguesía administrativa, en la que encontramos, por este orden, a:

letrados (escribanos, notarios, abogados, procuradores, letrados de consejos, audiencias y chancillerías). Por ejemplo, el lectoral Gregorio Sánchez de Lerma (+1597), hijo del licenciado Bernaldo de Lerma, abogado del cabildo; el canónigo Gracián de Briviesca, hijo del licenciado Juan Sánchez de Briviesca (+1534), alcalde mayor de Galicia, alcalde de Casa y Corte y juez del corregidor de Toledo; o el racionero Alonso Fariña (+1572), hijo de Alonso Fariña, notario de Santiago y escribano de la audiencia arzobispal.

${ }^{29}$ En las tres primeras columnas figura el nombre del capitular, la primera prebenda y el año en que toma posesión de ella; después figura el nombre del padre y el beneficio o estado eclesiástico del mismo al nacer su hijo, colocando entre paréntesis la prebenda capitular compostelana que ocuparon antes o después del nacimiento. En cursiva figuran datos probables o supuestos.

${ }^{30}$ A. IGLESIAS ORTEGA (2011): «La perpetuación de la sangre: la descendencia ilegítima del alto clero compostelano en el siglo XVI», Manuscrits, 29 (en prensa). 
regidores. Por ejemplo, el arcediano Pedro de Ben (+1525), hijo de Fernando de Ben, jurado y regidor de Noia; el canónigo Jerónimo López Gallo y el deán Baltasar López Gallo, hijos del mercader Diego López Gallo, regidor de Castrojeriz; el canónigo Alfonso Ares del Villar, hijo del regidor compostelano Pedro da Fraga (+1569); o los canónigos Gabriel y Simón Rodríguez (+1555?), hijos del regidor de Pontevedra, Jácome Rodríguez.

oficios concejiles menores (alcaldes, jurados, alguaciles). Por ejemplo, el canónigo coadjutor Ares González del Villar, hijo del ciudadano Juan Ares del Vilar (+1530), alcalde ordinario de Santiago; o el canónigo Pedro de Alemparte y Correa (+1605), hijo de Pedro de Alemparte, jurado de Tui.

$\checkmark$ oficios de la administración real y señorial (jueces, recaudadores, alguaciles). Por ejemplo, el deán Diego de Muros (+1525), nieto paterno de Diego Rodríguez, juez de Muros; o el canónigo Jerónimo de Baltanas Moscoso, hijo de Pedro de Baltanás (+1541), recaudador de rentas reales de Noia.

otras profesiones liberales (médicos). Se trata del canónigo Fernando Álvarez Maldonado, hijo del famoso "Doctor de la Reina", doctor Fernando Álvarez Abarca (+1526), médico de Cámara de los Reyes Católicos y de la Casa de la reina Juana de Castilla; del canónigo Gaspar Bermejo (+1608), hijo del doctor Andrés Bermejo, médico de Felipe III; y del citado prior Francisco Valles y Vera, hijo del "Divino Valles" (+1592), protomédico general de Castilla.

Un 9,91\% corresponde a la que hemos denominado burguesía económica, compuesta, en primer lugar, por profesionales del sector del comercio (mercaderes, cambiadores, otros comerciantes) ${ }^{31}$, al que hemos añadido algún profesional como los boticarios (es el caso del lectoral Tomás de Baeza Polanco, fallecido en 1606, hijo del boticario burgalés Francisco de Baeza), que no podemos equiparar a los médicos por no contar con estudios universitarios, y, en un segundo plano, por artesanos enriquecidos. Por ejemplo, el canónigo y futuro obispo de Trípoli Pedro Gil Falcón (+1549), hijo del platero compostelano Pedro Gil; el racionero Alonso

${ }^{31}$ Por ejemplo, los canónigos Pedro y Juan de Lemos (+1540), hijos del mercader compostelano Gonzalo de Lemos "el Viejo"; el canónigo Juan de Luaces (+1529), miembro del poderoso linaje mercantil de los Luaces; o el racionero Gonzalo Abril (+1546), hijo de Gonzalo Abril, cambiador mayor de la Iglesia de Santiago, perteneciente a un antiguo linaje burgués compostelano. 
Rodríguez de Saavedra (+1572), hijo del zapatero compostelano Jácome Afonso; o el racionero Pedro da Cal (+1558), tío del sastre Fernando da $\mathrm{Cal}^{32}$.

Finalmente, hay que destacar otro $10,21 \%$ de capitulares que, al no conocer la profesión del padre o abuelo paterno, podemos considerar sin mayor precisión dentro de las élites urbanas, gracias al análisis de sus relaciones personales y de sus parentescos maternos y políticos. Por ejemplo, los racioneros Pedro de Rubiel (+1561) y su sobrino Bartolomé García (+1575) están emparentados con un platero y un tondidor compostelanos, y la madre de este último, María García de Rubiel, está en conexión con varios mercaderes. O también el canónigo Juan López Pombo (+1581), que casó a sus sobrinas con un platero y un mercader compostelanos, y que estaba endeudado con varios mercaderes ${ }^{33}$. No sabemos si el peso de estas élites urbanas era similar en otros cabildos castellanos, pero, por ejemplo, en el de la Barcelona del XVII su proporción era menor $(23,58 \%)$, registrando un mayor peso del sector artesanal que del mercantil y administrativo (letrados y militares), debido al control que la nobleza ejercía sobre los puestos capitulares y a la menor importancia demográfica de esos sectores en la ciudad condal ${ }^{34}$.

En cuanto a la procedencia geográfica de los capitulares cuyo origen social se puede situar entre estos grupos urbanos de poder, nos encontramos con que el $36,21 \%$ de la muestra es de origen local, pero, al contabilizar a todos los gallegos, llegamos al 61,21\%. Por categorías socioeconómicas, dejando de lado el importante contingente sin especificar, en el que la mayoría son de origen foráneo, la muestra nos da un $42 \%$ (ampliable al 58\%, considerando a todos los gallegos) y un $45,45 \%$ (ampliable al 90,91\%, considerando a todos los naturales de Galicia) de capitulares locales procedentes de la burguesía administrativa y de la burguesía económica, respectivamente. Esto nos demuestra el gran peso numérico que en el cabildo tienen las élites urbanas gallegas (recordemos: sin contar a sus miembros ennoblecidos) y que los capitulares pertenecientes a las foráneas se mueven, sobre todo, dentro de las oligarquías municipales castellanas de regidores, letrados y mercaderes. En conjunto, las oligarquías municipales tenían un peso superior al cuantificado numéricamente. Sólo hace falta comparar el número conocido de

32 Todos ellos entrarían dentro del escalafón superior del sector artesanal que Juan Gelabert denominó "artesanado independiente": "Se trata de gentes con negocio abierto, con un taller o casataller, dueños de su utillaje, gerentes de su proceso productivo, pero naturalmente sujetos en otro importante asunto: la provisión de ciertas materias primas. Abarca los oficios más diversos: plateros, sastres, curtidores, herreros, canteros, etc.” (J. E. GELABERT GONZÁLEZ (1982). Op. cit., pp. 307-310).

${ }^{33}$ Véase sobre este personaje lo dicho en ibid., pp. 285 y 298.

${ }^{34}$ Cálculo elaborado a partir de los datos ofrecidos en P. FATJÓ GóMEZ (1993). Op. cit., pp. 155156. 
capitulares hijos de regidores (20) con el de capitulares emparentados en grado próximo con alguno de ellos $(81)^{35}$. Más esclarecedor incluso es, en el caso de las oligarquías compostelanas, acudir a la lista de regidores de Santiago para comprobar que más de un $60 \%$ comparten los apellidos o están emparentados con algún miembro del cabildo en el siglo $\mathrm{XVI}^{36}$. Según Antonio Irigoyen, en un cabildo como el de Murcia, donde sólo una quinta parte de los principales linajes de la ciudad estaba presente en sus filas, el desinterés de la oligarquía local se debía a diversos factores como la baja natalidad legítima de las élites murcianas, el elevado coste económico y social que representaba el acceso a las prebendas, las limitaciones impuestas por Trento $y$, sobre todo, la procedencia predominantemente foránea de los capitulares ${ }^{37}$.

Lo que hemos dado en llamar élites rurales alcanza al 6,61\% de los capitulares: $4,80 \%$ sin mayor especificación y $1,80 \%$ de "labradores". La mayoría son hijos de campesinos ricos que han alcanzado un nivel económico suficiente como para ascender en el escalafón social, desarrollando prácticas propias de las élites, como, por ejemplo, adoptando una política matrimonial con miembros de las oligarquías rurales y, en algún caso, de las élites urbanas o incluso de la hidalguía ${ }^{38}$, invertir sus ganancias en la adquisición de tierras y rentas $^{39}$, llevar un estilo de vida acomodado o, en fin, invertir en la formación académica de alguno de sus vástagos

${ }^{35}$ Hemos considerado a aquellos capitulares que por sí mismos ocuparon algún regimiento (2). El estudio de los testamentos de capitulares canarios nos da unos porcentajes muy elevados de hijos $(26,9 \%)$ y hermanos $(34,6 \%)$ de regidores (P. C. QuinTANA ANDRÉS (2004). Op. cit., p. 130).

${ }^{36}$ Cálculo elaborado a partir de los datos extraídos de las actas municipales de Santiago conservadas entre 1500 y 1560 (AHUS, Archivo Municipal, Libros de Actas nos 2-4) y de M. LóPEZ DíAZ (1994). Op. cit., pp. 291-292.

37 A. IRIGOYEN LÓPEZ (2000). Entre el cielo y la tierra, entre la familia y la institución. El cabildo de la catedral de Murcia en el siglo XVII. Murcia: Universidad de Murcia, pp. 172-175.

${ }^{38}$ Por ejemplo, Fernán de Castroverde y su mujer Beatriz de Castroverde, padres del racionero Antonio Fernández de Castroverde $(+1550)$, casaron a su hija con un carpintero y luego con un mercader compostelanos; Juan Herrero de Caviedes, natural del lugar de Capillas (León), padre del canónigo Domingo Blanco de Caviedes, había casado con María Blanca, hermana del arzobispo Francisco Blanco, de los Blanco de Salcedo, hidalgos de dicho pueblo.

39 Por ejemplo, Alonso de Castro y su mujer Herena de Castro, vecinos de San Breixome das Donas, padres del canónigo Álvaro de Castro, compraron a Catalina de Mena, viuda de Nuño Álvarez de Sebil, vecina de Santiago (3/12/1547), la cuarta parte entera del lugar y casal de Carballal (San Lourenzo de Pousada), que entonces labraba Jácome Cao y que rentaba anualmente una fanega de trigo y una gallina, en precio de 17 ducados de oro (AHUS, Protocolos Notariales, Santiago de Compostela, 211, fols. 729-730v). También tenía dicho Alonso de Castro un foro en el lugar de Castro (Santiago de Prevediños), por cuya propiedad hubo de concertarse con un calcetero compostelano el 10/9/1558 (ibid., 262, fol. 62-62v). 
para colocarlo en algún puesto burocrático o eclesiástico, con el que incrementar el prestigio y patrimonio familiar ${ }^{40}$. De la muestra recogida, el $45,45 \%$ proceden de la diócesis compostelana, porcentaje ampliable al $81,81 \%$ si consideramos a todos los naturales de Galicia. Esto parece indicar que sólo los grupos rurales más vinculados al entorno compostelano pueden alcanzar alguna prebenda en su cabildo. Los elementos foráneos se reducen a capitulares de oposición (el lectoral Diego de Alba, el penitenciario Gómez Cuesta y el maestro de capilla Francisco de Logroño) o a individuos vinculados al arzobispo de turno (el cardenal Domingo Blanco de Caviedes era sobrino del arzobispo Blanco). Uno de ellos, al menos, quizás fuese hidalgo y, en ese caso, debería estar contabilizado dentro de las clases privilegiadas ${ }^{41}$. En cualquier caso, este colectivo representa una parte muy pequeña en el conjunto de los capitulares de Santiago ${ }^{42}$.

El análisis por tipo de prebenda completa la visión sobre su origen social ${ }^{43}$. Como es lógico, cuanta mayor calidad tiene la prebenda, más elevado es el rango social del prebendado ${ }^{44}$. Si entre los racioneros poco más de la tercera parte

${ }^{40}$ Son varios los estudiantes de colegios mayores y menores: el cardenal Domingo Blanco de Caviedes, en Santa Cruz de Cañizares; el lectoral Diego de Alba en el del Arzobispo de Salamanca; el penitenciario Francisco Gómez Cuesta, en el de los Teólogos de Alcalá (su padre Francisco Gómez era natural de la villa de Peñafiel, pero labrador, de ahí que lo consideremos de ámbito rural y no urbano); el racionero Alonso de Moimenta, en el de Fonseca de Santiago; el canónigo Eliseo de las Alas Noboa en el mismo.

${ }^{41}$ El canónigo Eliseo de las Alas Noboa, hijo de Rosendo Salgado, vecino de San Mamede Grou, tal vez fuese hidalgo descendiente de los Salgado orensanos, pero al no tener la seguridad absoluta, nos hemos decantado por situarlo entre las oligarquías rurales.

${ }^{42}$ Mucho mayor $(14,15 \%)$ será el peso del sector primario (labradores y pescadores) dentro de la catedral barcelonesa del XVII (cálculo elaborado a partir de los datos ofrecidos en P. FATJÓ GómEZ (1993). Op. cit., pp. 156-157).

43 Puede verse un análisis similar por tipología capitular para el clero catedralicio de Lleida durante el período 1700-1750, con un cabildo pequeño caracterizado por su extracción eminentemente local y rural. La muestra manejada parte de la información ofrecida por los testamentos de 58 clérigos. Dejando al margen los clérigos cuyo origen social se ignora $(23,21 \%)$, las dignidades y canonjías presentan un $18,18 \%$ de nobles y un $9,09 \%$ de comerciantes frente a un $63,64 \%$ de campesinos y un $9,09 \%$ de artesanos, mientras que los racioneros, beneficiados y capellanes alcanzan sólo un 6,25\% de comerciantes frente a un 78,13\% de campesinos y un 15,62\% de artesanos (cálculos elaborados a partir de los datos ofrecidos por M. À. CHAUBEL I CABRERA (1999). «L'extracció social i geogràfica de la clerecia lleidatana del Set-cents». En MARTÍNEZ SHAw, C. (ed.). Historia moderna, historia en construcción. Sociedad, Política e Instituciones. Lleida: Editorial Milenio, vol. II, p. 59).

${ }^{44}$ Un ejemplo cercano lo tenemos en la cúspide de la jerarquía eclesiástica gallega, cuyos obispos proceden del estamento nobiliario en un 91,11\% para el período 1600-1649 (M. BARRIO GozALO (1985). «Perfil socio-económico de una élite de poder (III): Los Obispos del Reino de Galicia (16001840)». Anthologica Annua, 32, p. 37). Además, se puede percibir una desigual proporción de los 
procede de los grupos privilegiados, entre los canónigos de oficio el porcentaje alcanza a casi el 39\%, entre los canónigos se eleva a casi el $58 \%$ y entre las dignidades se acerca a las tres cuartas partes. De igual modo, las categorías nobiliarias y eclesiásticas de mayor rango están más representadas en las prebendas superiores: la nobleza titulada sólo se da entre canónigos y dignidades, y las órdenes militares y caballeros hijosdalgo entre estas últimas; el único hijo de prelado fue el arcediano de Nendos Alonso de Fonseca (III), hijo del arzobispo Fonseca II. Por contra, el porcentaje referido a las élites urbanas va decreciendo a medida que ascendemos de escalafón: la mitad de todos los racioneros, poco más de un $44 \%$ de los canónigos de oficio, poco más de un $37 \%$ de los canónigos atitulados y un $22 \%$ de las dignidades. La importancia relativa de la burguesía administrativa, especialmente regidores, se incrementa cuanto mayor es la posición de la prebenda, mientras que la de la burguesía económica, especialmente artesanos, se reduce. De modo similar a las élites urbanas opera la proporción relativa a las élites rurales, es decir, menor cuanto mayor el grado capitular: desde el 13\% de los racioneros hasta el casi $4 \%$ de las dignidades. Sólo el porcentaje de las canonjías de oficio es algo superior al de los racioneros $(16,67 \%)$, pero hay que tener en cuenta que el conocimiento de la extracción social de estos últimos es mucho menor que el del resto de capitulares. Además, la oposición era la vía de acceso al cabildo más democrática de todas cuantas había, en la que pesaba la preparación y pericia del aspirante por encima de las recomendaciones, el poder económico o el estatus social, lo que daba a las familias de campesinos enriquecidos un pequeño resquicio para la promoción de sus vástagos. Cabe señalar, por último, que la proporción de hijos de clérigos es mayor entre racioneros y canónigos (en torno al 16\% de media) que entre canónigos de oficio y dignidades (10,77\% de media), quizás porque entre estos hubo um mayor peso de los colegiales mayores, a los que se solía exigir una calidad moral intachable y una pureza de sangre, en la que la ilegitimidad no estaba contemplada.

\section{LIMPIEZA DE SANGRE: ASCENDENCIA JUDEOCONVERSA DE CAPITULARES}

La irrupción de los estatutos de limpieza de sangre ha sido entendida como un claro exponente del temor de las clases privilegiadas al ascenso social de los grupos inferiores y un instrumento para imponer el sistema de valores de las primeras, es decir, la denominada cultura de las élites, que permitiría asimilar dentro de estas a elementos procedentes de las clases populares, pero con

grupos privilegiados no sólo en función de la categoría de la prebenda, sino también en función de la categoría del cabildo (P. LOUPÈs (1985). Op. cit., p. 242). 
comportamientos propios de aquellas ${ }^{45}$. Aunque ya aparecen en el siglo $\mathrm{XV}$, se generalizan en el siguiente y su adopción por los cabildos eclesiásticos seculares se produce fundamentalmente a lo largo de su segunda mitad. Precisamente de mediados de esta centuria (1545) son las pruebas de limpieza de sangre más antiguas que se conservan del cabildo compostelano ${ }^{46}$. Esta limitación cronológica deja toda la mitad del siglo sin una fuente importante de conocimiento sobre la presencia de capitulares con mácula en su familia. El número de expedientes conservados en los años restantes tampoco es muy elevado (sólo 19 completos) ${ }^{47}$. Por lo tanto, hemos tenido que buscar expedientes de limpieza de estos individuos en otras instituciones de estatuto, en las que el problema de conservación y de implantación también inciden en su utilidad: descartados los procedentes de otros cabildos peninsulares donde hubiesen disfrutado de una prebenda por el esfuerzo de movilidad geográfica, hemos recurrido a los expedientes de colegiales mayores (Santiago, Salamanca, Valladolid y Alcalá) y a los de miembros de la Inquisición (conservados fundamentalmente en el Archivo Histórico Nacional). Junto a estas fuentes, nos hemos apoyado en los estudios existentes sobre conocidas personalidades o familias judeoconversas. Sin embargo, el resultado ha sido más bien escaso: de todos los capitulares, sólo en nueve casos hay certeza o sospecha de un lejano origen converso o judaizante; en un caso, un parentesco con personas ajusticiadas, y, en otro, unas ascendientes acusadas de brujería.

Respecto a los primeros, la generación marcada por el sambenito de la sangre judía o conversa está, en general, por encima de los bisabuelos o en un grado de afinidad lejano: Pedro de Torquemada, arcediano de Salnés (+1527), era sobrino de Francisco de Torquemada, nepote del famoso cardenal Juan de Torquemada, al parecer judeoconverso por parte de madre ${ }^{48}$; un cuñado del canónigo Andrés

45 El tema de la limpieza de sangre ha sido ampliamente tratado a partir de los trabajos de Domínguez Ortiz y Albert Sicroff (A. Domínguez ORTIZ (1991). La clase social de los judíos en Castilla en la Edad Moderna. Granada: Universidad de Granada; A. A. Sicroff (1985). Los estatutos de limpieza de sangre. Controversias entre los siglos XV y XVII. Madrid: Taurus). Sobre su implantación y desarrollo en cabildos catedralicios se ha publicado muchísimo. Un buen ejemplo puede ser J. HERNÁNDEZ FRANCO (1996). Cultura y limpieza de sangre en la España moderna: puritatis sanguinis. Murcia: Universidad de Murcia.

${ }^{46}$ Sobre sobre su implantación y características, véase A. IGLESIAS CASTELAO (1996). Op. cit., pp. 421-450.

${ }^{47}$ Ibid., p. 425.

48 Archivio Segreto Vaticano, Registri Vaticani, 742, fols. 37v-39v; V. BELTRÁn DE HEREDIA (1972). Miscelánea Beltrán de Heredia. Colección de artículos sobre historia de la teología española. T. I, Salamanca: Editorial OPE, pp. 276-386. 
Ortega de Cerezo (+1548) era descendiente de estos mismos Torquemada ${ }^{49}$; el canónigo Gonzalo Fernández de Puebla (1533-1534), acaso pudiera ser el mismo Gonzalo Fernández, chantre de la ciudad de Londres, hijo y heredero del oscuro doctor Gonzalo Fernández de Puebla, embajador de los Reyes Católicos en Londres, de ascendencia conversa ${ }^{50}$; el canónigo Juan Fernández de Torres (15341538), prior de Palencia, era hijo de un Gómez Fernández de Córdoba, que pudiera ser de origen converso ${ }^{51}$; el racionero Gabriel de Palomares y Eraso (+1563), sobrino del conocido secretario Eraso, tuvo que someterse a varias pruebas de limpieza de sangre a lo largo de su vida por el supuesto origen villano o converso de su abuela materna, si bien es cierto que algunos de los testimonios en su contra estaban bajo sospecha de enemistad manifiesta por razones políticas ${ }^{52}$; el arcediano de Cornado Francisco de Mendoza y Bobadilla (+1566), autor del polémico Tizón de la Nobleza, debió olvidar que sus bisabuelos maternos eran de origen converso y que las mujeres de dos hermanos de su abuelo materno también lo eran ${ }^{53}$; el arcediano de Nendos Luis de Torres (+1584) era nieto paterno de un malagueño cuya primera esposa era hija de unos mercaderes conversos condenados por el Santo Oficio ${ }^{54}$; el canónigo Jerónimo de Baltanás (+1591) era hijo de un recaudador mayor de las rentas reales de Noia, que seguramente estuviese

49 ARChivo HistóRICo Viana. El mayorazgo de los Ortega Cerezo de Torquemada [recurso electrónico]. Genealogías. <http://www.archivohistoricoviana.es/documentos/ El_ Mayorazgo _de _ los_Ortega_Cerezo_de_Torquemada.pdf> [Consultado: 05-03-2011].

${ }^{50}$ Archivo General de Simancas, Cámara de Castilla (CCA), Libros registros de cédulas (CED), Libros generales de la Cámara, lib. 7, 222, 3; L. SuÁREZ FERNÁNDEZ (1990). Los Reyes Católicos. El camino hacia Europa. Madrid: Rialp, p. 168.

51 J. SAn Martín PAyo (1983). «Catálogo del Archivo de la Catedral de Palencia». Publicaciones de la Institución Tello Téllez de Meneses, no 50, pp. 303-304; E. ORTEGA GATO (1950). «Blasones y mayorazgos de Palencia», Publicaciones de la Institución Tello Téllez de Meneses, $\mathrm{n}^{\circ}$ 3, pp. 209-210.

52 Archivo Universitario de Salamanca, Fondo Universitario, 2323, fols. 477-517.

53 M. del P. RÁBADE OBRAdó (2006). «La invención como necesidad: genealogía y judeoconversos». En LADERO QUESADA, M. Á. (coord.). Estudios de genealogía, heráldica y nobiliaria. Madrid: Universidad Complutense, pp. 183-201; ÍDEM (1993). Una élite de poder en la Corte de los Reyes Católicos. Los judeoconversos. Madrid: Sigilo, pp. 173-226; J. I. ORTEGA CERVIGÓN (2006). La acción política y la proyección señorial de la nobleza territorial en el obispado de Cuenca durante la Baja Edad Media. Madrid: Universidad Complutense (tesis doctoral), pp. 210213.

54 J. C. GonZÁLEZ TERnERo. Linajes de Málaga. Genealogía Torres-de la Bandera [recurso electrónico]. Linajes malagueños. <http://ficus.pntic.mec.es/jgot0016/Linajesdemalaga/\# Córdobatorres $>$ [Consultado: 05-03-2011]. 
emparentado con los Baltanás judíos de Palencia $^{55}$; finalmente, tres de los bisabuelos del lectoral Tomás de Baeza Polanco (+1606) fueron hijos de judíos relajados por el Santo Oficio ${ }^{56}$. Sólo en dos de estos individuos se ha partido de la información facilitada por un expediente de limpieza de sangre, concretamente, el de colegial de Oviedo en Salamanca (1563) para Gabriel de Palomares y el de inquisidor de Valladolid para Tomás de Baeza (1596); el resto procede de fuentes bibliográficas u otras menores. Es decir, ningún expediente de limpieza realizado por los escrutadores del cabildo compostelano proporciona pistas sobre la ascendencia conversa de capitulares de Santiago. Como se puede comprobar, todos los casos son de individuos nacidos fuera de Galicia.

Es evidente que, dado que las pruebas conservadas son las de aquellos que las han pasado, difícilmente puede constar la mácula judía de ningún informado y que, precisamente, la propia existencia de un estatuto de limpieza pretendía disuadir de intentar alcanzar una prebenda capitular a cualquier aspirante con tal defecto. Sin embargo, también es cierto que, hasta la implantación de dicho estatuto en el cabildo y la del Tribunal de la Inquisición en Galicia, hubo oportunidades para que descendientes de judeoconversos pudieran "blanquear" su sangre obteniendo un puesto en la jerarquía eclesiástica compostelana. Además, la implantación definitiva de ambas instituciones no se producirá hasta la siguiente centuria $\mathrm{y}$, lo que es más determinante a nuestro juicio, la firmeza de sus actuaciones variará dependiendo del momento.

En cuanto a las informaciones de limpieza del cabildo, en el siglo XVI no van más allá de los abuelos (cuando no de los padres) y no se preocupan tanto de otros parientes ni de los "actos positivos" de sus familiares. Ni siquiera la actividad inquisitorial, mucho más beligerante en la segunda mitad del XVI que en todo el XVII, estimula la práctica de la limpieza de sangre en los últimos años de la centuria -recordemos que el tribunal no se instala definitivamente en Santiago de Compostela hasta 1574, después de dos largos intervalos bajo el control directo del Tribunal de Valladolid-. Los dos objetivos principales del Tribunal de Galicia hasta 1600 son la represión del luteranismo y la "recristianización" del territorio gallego sobre las bases del Concilio, mientras que el interés por los judaizantes tiene mucho menor relieve, como lo demuestra el hecho de que únicamente se hubiese procesado a 4 judaizantes en el período 1560-1599. Los primeros pasos de la

55 AHUS, Protocolos Notariales, Santiago de Compostela, 81, fols. 120-227; A. CABEZA (1996). Clérigos y señores. Política y religión en Palencia en el Siglo de Oro. Palencia: Diputación Provincial de Palencia, p. 101.

${ }^{56}$ Archivo Histórico Nacional, Inquisición, leg. 1572, nº 10. 
Inquisición en Galicia se remontan a la década de 1520, justo cuando se produce la instalación de judaizantes portugueses en las zonas marítimas de los pueblos fronterizos, huyendo de la Inquisición de su país, pero su persecución no se intensifica hasta que se suceden las conspiraciones de principios de la siguiente centuria. Además, el Santo Oficio se ensañará fundamentalmente con los delitos cometidos por el sustrato campesino y la jerarquía eclesiástica escapa de sus manos. De hecho, es bien conocida la oposición del cabildo a la instauración de la Inquisición en la ciudad, motivada, sobre todo, por el deseo de la Iglesia compostelana de mantenerse como la única instancia con jurisdicción en los asuntos de fe y moral, y las reticencias a suprimir una de sus canonjías a favor del fisco inquisitorial ${ }^{57}$. También hay que tener en cuenta el tradicional poder económico de las comunidades judías y conversas, vinculados a las finanzas de los poderosos (reyes, nobles, Iglesia) ${ }^{58}$ y con un papel clave como mercaderes y prestamistas, lo que contribuyó al mantenimiento de una actitud más relajada hacia ellos, aún después de la expulsión de los judíos decretada en 1492, sobre todo en el período de crisis demográfica y agrícola que vivió Galicia desde finales de los 60 y cuyas más duras manifestaciones arreciaron en los 80 y 90 del XVI, justo cuando se produce un descenso en el ritmo de los expedientes de limpieza del cabildo compostelano $^{59}$.

En fin, aunque muy minoritaria, está probada la ascendencia judeoconversa, aunque difusa, en las genealogías de algunos capitulares compostelanos de origen foráneo, pero, en general, se pueden considerar excepciones asumidas por el cabildo en tanto en cuanto se trataba en muchos casos de individuos procedentes de otras instituciones y que ya venían con un expediente bajo el brazo, el cual garantizaba su limpieza de sangre. Y en cuanto a los capitulares de origen gallego, podemos presumir una mayor flexibilidad ante el componente converso, sobre todo en las primeras décadas y en las últimas de siglo, especialmente para aquellos prebendados de origen portugués o que nacieron en alguno de los puntos limítrofes con Portugal, donde se concentraron los emigrantes judíos, o en aquellos lugares donde estaban asentadas las juderías gallegas más importantes (Ourense,

\footnotetext{
57 Sobre la Inquisición en Galicia es básica la obra de J. CONTRERAS (1982). El Santo Oficio de la Inquisición de Galicia, 1560-1700. Poder, sociedad y cultura. Madrid: Akal Editor.

58 Podemos destacar el caso del judío Judá Pérez, que estuvo al servicio del conde de Ribadavia, del señor de Allariz y del conde de Santa Marta en el último cuarto del siglo XV (M. G. de ANTONIO Rubio (2005). «Estancia de Luis Alonso, antes llamado Judá Pérez, en Galicia”. Espacio, Tiempo y Forma. Serie III, Historia Medieval, t. 18, pp. 27-37).

59 A. Iglesias CASTElaO (1996). Op. cit., pp. 426-427.
} 
Ribadavia, Tui, Allariz, A Coruña) ${ }^{60}$. Es más probable que, si los hubiera habido, los capitulares compostelanos de origen converso o judaizante hubiesen sido anteriormente prebendados en cabildos de ciudades gallegas con un importante peso de sus comunidades judías: Tui y Ourense ${ }^{61}$.

Para terminar, fuera de la mácula judaica, hemos hallado, por un lado, una mención herética relacionada con el canónigo Juan López de San Juan (+1567), concretamente con su barragana Teresa do Carballal, madre de sus hijos, natural de San Miguel de Maceda (Lugo), que tuvo fama de hechicera, al igual que su abuela Catalina de Maceda, según se testimoniaba en el expediente para colegial de Fonseca de un nieto de aquella $(1633)^{62}$. Por otro lado, el racionero Alonso de Moimenta (+1548) estuvo emparentado -según el expediente para colegial de Fonseca realizado a un nieto suyo (1594)- con una mujer llamada "A Varreira" que había sido ahorcada, posiblemente la misma cuyo hijo había sido ahorcado en A Coruña por haber matado a un clérigo ${ }^{63}$.

${ }^{60}$ M. G. DE Antonio Rubio (2004). «Distribución urbana de la minoría judía en Galicia: la judería». Cuadernos de Estudios Gallegos, vol. LI, 117, pp. 263-279.

${ }^{61}$ Pueden verse algunos ejemplos de las relaciones entre estos cabildos y los judíos en ÍDEM (2007). «Judíos en Galicia: visión panorámica y nuevas aportaciones documentales». Espacio, Tiempo y Forma. Serie III, Historia Medieval, t. 20, pp. 301-314.

62 AHUS, Fondo Universitario, Serie Histórica 205, Colegio de Fonseca, Informaciones de Limpieza de Sangre, exp. $\mathrm{n}^{\circ} 13$.

63 AHUS, Fondo Universitario, Serie Histórica 367, Colegio de Fonseca, Informaciones de Limpieza de Sangre, Expediente de Antonio Martínez; ibid., Serie Histórica 432, Colegio de Fonseca, Provisión de becas, exp. $\mathrm{n}^{\mathrm{o}} 1$. 
Tabla no 3. Capitulares compostelanos hijos de clérigos

\begin{tabular}{|c|c|c|c|c|}
\hline Nombre del hijo & Prebenda & Año & Nombre del padre & Estado/beneficio \\
\hline Alonso de Fonseca & $\begin{array}{l}\mathrm{Arc}^{\circ} \\
\text { Cornado }\end{array}$ & 1484 & Alonso de Fonseca II & $\operatorname{Arz}^{\circ}$ Stgo \\
\hline Juan de Alderete & $\mathrm{Arc}^{\circ}$ Salnés & 1550 & ¿? & Clérigo \\
\hline Alonso Rodríguez de León & Cardenal & 1571 & Diego de León & Maestrescuela Oviedo \\
\hline Alonso López de Buela & Card (coadj) & 1546 & Juan de Buela & $\mathrm{Can}^{\circ}$ Stgo \\
\hline Bernaldino Melgarejo & Chantre & 1530 & Juan Melgarejo & Chantre Stgo \\
\hline Juan Álvarez de Canabal & Prior Sar & 1526 & Jácome Álvarez & Prior Sar \\
\hline Diego Vallo & Tesorero & 1509 & ¿? & Presb $^{\circ}$ \\
\hline Juan López de Valladolid & Canónigo & 1487 & Alonso López de Valladolid & Diácono(d. $\operatorname{arc}^{o}$ Salnés $)$ \\
\hline Juan Rodríguez & Canónigo & 1491 & Alfonso Rodríguez de La Cruña & $\mathrm{Can}^{\circ} \mathrm{Stgo}$ \\
\hline Juan Micael de Ben & Canónigo & 1498 & Pedro de Ben & $\operatorname{Presb}^{\circ}$ (d. arc $^{\circ}$ Trastámara) \\
\hline Pedro Beltrán & Canónigo & 1502 & Pedro Beltrán & $\operatorname{Presb}^{\circ}$ (d. $\operatorname{arc}^{\circ}$ Nendos $)$ \\
\hline Bartolomé López & Canónigo & 1506 & Juan López de Valladolid & $\mathrm{Can}^{\circ}$ Stgo \\
\hline Pedro de Vaamonde & Canónigo & 1507 & Francisco de Vaamonde & $\mathrm{Can}^{\circ} \mathrm{Stgo}$ \\
\hline Pedro de Castilla & Canónigo & 1508 & Diego de Castilla & Maestrescuela Stgo \\
\hline Fernando de la Torre "el Mozo" & Canónigo & 1515 & $\begin{array}{l}\text { Fernando de la Torre "el } \\
\text { Viejo" }\end{array}$ & $\mathrm{Can}^{\circ} \mathrm{Stgo}$ \\
\hline Jácome de Ben & Canónigo & 1518 & Pedro de Ben & $\operatorname{Arc}^{\circ}$ Trastámara \\
\hline Diego de Castilla & Canónigo & 1524 & Diego de Castilla & Maestrescuela Stgo \\
\hline Juan Bernal Díaz de Luco & Canónigo & 1529 & Cristóbal Díaz & $\operatorname{Rac}^{\circ}$ Sevilla \\
\hline Pedro de Soto "el Mozo" & Canónigo & 1530 & Pedro de Soto & $\operatorname{Presb}^{\circ}\left(d . \operatorname{can}^{o}\right.$ Stgo $)$ \\
\hline Jácome de Puga "el Mozo" & Canónigo & 1533 & Jácome de Puga "el Viejo" & Cardenal Stgo \\
\hline Fernando de Corneda "el Mozo" & Canónigo & 1534 & $\begin{array}{l}\text { Fernando de Corneda "el } \\
\text { Viejo" }\end{array}$ & $\mathrm{Can}^{\circ}$ Stgo \\
\hline Sancho de Ulloa & Canónigo & 1536 & ¿? & $\mathrm{Can}^{\circ}$ Stgo \\
\hline Lope Sánchez de Ulloa & Canónigo & 1536 & Juan Rodríguez de Ulloa & Juez Luou \\
\hline Juan López de San Juan & Canónigo & 1537 & ¿? & Presb $^{\circ}$ \\
\hline Juan Sarmiento & Canónigo & 1540 & Pedro Sarmiento & Capellán (d. arzo Stgo) \\
\hline Diego Rodríguez de Moscoso & Canónigo & 1542 & ¿? & Clérigo \\
\hline Fernando Ares del Villar & Canónigo & 1543 & Miguel Rodríguez del Villar & $\mathrm{Can}^{\circ} \mathrm{Stgo}$ \\
\hline Juan de Ozpina "el Mozo" & Canónigo & 1551 & Juan de Ozpina de Salinas & $\operatorname{Presb}^{\circ}$ (d. $\operatorname{arc}^{\circ}$ Cornado) \\
\hline Juan Patiño & Canónigo & 1560 & Juan Patiño Giance "el Viejo" & $\mathrm{Can}^{\circ} \mathrm{Stgo}$ \\
\hline Pedro García Raposo "el Mozo" & Canónigo & 1563 & $\begin{array}{l}\text { Pedro García Raposo "el } \\
\text { Viejo" }\end{array}$ & $\mathrm{Can}^{\circ}$ Stgo \\
\hline Francisco Sánchez de Vaamonde & Canónigo & 1565 & Juan López de Gaibor & Presb $^{\circ}$ \\
\hline Francisco Estaquero & Canónigo & 1566 & ¿? & Clérigo \\
\hline Rodrigo de Osma Delgado & Canónigo & 1574 & Luis Delgado "el Mozo" & $\mathrm{Can}^{\circ}$ Badajoz \\
\hline Álvaro Pérez de Osma & Canónigo & 1575 & Luis Delgado "el Mozo" & $\mathrm{Can}^{\circ}$ Badajoz \\
\hline Fructuoso Romero & $\mathrm{Can}^{\circ}($ coadj $)$ & 1542 & Martín Romero & Cardenal Stgo \\
\hline Diego Maldonado de la Carrera & $\mathrm{Can}^{\circ}($ coadj $)$ & 1563 & Pedro Maldonado de la Carrera & $\mathrm{Can}^{\circ}$ Stgo \\
\hline Diego Gómez Bermúdez de Castro & $\mathrm{Can}^{\circ}($ coadj $)$ & 1540 & Fernando Bermúdez de Castro & $\mathrm{Can}^{\circ}$ Stgo \\
\hline Juan García & $\mathrm{Can}^{\circ}$ (coadj) & 1541 & $\begin{array}{l}\text { Pedro García Raposo "el } \\
\text { Viejo" }\end{array}$ & $\mathrm{Can}^{\circ}$ Stgo \\
\hline Aníbal Rodríguez & $\mathrm{Can}^{\circ}($ coaj$)$ & 1550 & Gabriel Rodríguez & Deán Lugo (a. $\operatorname{arc}^{\circ}$ Reina) \\
\hline Gómez González de Chantreiro & $\mathrm{Can}^{\circ}$ lectoral & 1511 & ¿? & Presb $^{\circ}$ \\
\hline Diego Ares de Castroverde & Racionero & 1515 & $\begin{array}{l}\text { Pedro Fernández } \\
\text { Castroverde }\end{array}$ & Clérigo (d. cardenal Stgo) \\
\hline Alonso Yáñez Calviño & Racionero & 1494 & Juan Calviño & $\mathrm{Can}^{\circ}$ Stgo \\
\hline Gonzalo Fernández & Racionero & 1498 & Gonzalo Fernández & Capellán S. Benito \\
\hline Fernando López de San Juan & Racionero & 1551 & Juan López de San Juan & $\mathrm{Can}^{\circ} \mathrm{Stgo}$ \\
\hline Suero de las Alas & Racionero & 1539 & Eliseo de las Alas "el Viejo" & $\mathrm{Can}^{\circ} \mathrm{Stgo}$ \\
\hline Leonel Feijoo & Racionero & 1555 & Pedro Feijoo de Podentes & Rector Podentes \\
\hline Agustín de Mondragón & Racionero & 1555 & Juan de Mondragón & $\operatorname{Presb}^{\circ}$ (d. capitular Stgo $)$ \\
\hline
\end{tabular}


Árturo Iglesias Ortega

Tabla n' 4: Extracción social de los capitulares en función del tipo de prebenda

\begin{tabular}{|c|c|c|c|c|c|c|c|c|c|c|}
\hline \multirow{2}{*}{ Grupo socioeconómico } & \multicolumn{2}{|c|}{ Dignidades } & \multicolumn{2}{|c|}{ Canónigos } & \multicolumn{2}{|c|}{ C. Oficio } & \multicolumn{2}{|c|}{ Racioneros } & \multicolumn{2}{|c|}{ Total } \\
\hline & $n^{o}$ & $\%$ & $n^{o}$ & $\%$ & $n^{o}$ & $\%$ & $n^{o}$ & $\%$ & $n^{o}$ & $\%$ \\
\hline Clases privilegiadas & 57 & 54,81 & 107 & 41,47 & 7 & 28 & 19 & 18,10 & 190 & 38,62 \\
\hline Nobles & 50 & 87,72 & 75 & 70,09 & 6 & 85,71 & 12 & 63,16 & 143 & 75,26 \\
\hline Sin especificar & 5 & 10 & 15 & 20 & 1 & 16,67 & 0 & 0 & 21 & 14,69 \\
\hline Grandes & 1 & 2 & 0 & 0 & 0 & 0 & 0 & 0 & 1 & 0,70 \\
\hline Nobleza titulada & 3 & 6 & 2 & 2,67 & 0 & 0 & 0 & 0 & 5 & 3,50 \\
\hline Señores de jurisdicción & 8 & 16 & 7 & 9,33 & 1 & 16,67 & 3 & 25 & 19 & 13,29 \\
\hline Caballeros de hábito y & & & & & & & & & & \\
\hline comendadores & 2 & 4 & 0 & 0 & 0 & 0 & 0 & 0 & 2 & 1,40 \\
\hline Caballeros & 6 & 12 & 0 & 0 & 0 & 0 & 0 & 0 & 6 & 4,20 \\
\hline Señores de casa solariega & 0 & 0 & 4 & 5,33 & 0 & 0 & 0 & 0 & 4 & 2,80 \\
\hline Hidalguía & 25 & 50 & 47 & 62,67 & 4 & 66,67 & 9 & 75,00 & 85 & 59,44 \\
\hline Clero & 7 & 12,28 & 32 & 29,91 & 1 & 14,29 & 7 & 36,84 & 47 & 24,74 \\
\hline Sin especificar & 1 & 14,29 & 4 & 12,50 & 0 & 0 & 0 & 0 & 5 & 10,64 \\
\hline Prelados & 1 & 14,29 & 0 & 0 & 0 & 0 & 0 & 0 & 1 & 2,13 \\
\hline Capitulares & 4 & 57,14 & 22 & 68,75 & 0 & 0 & 3 & 42,86 & 29 & 61,70 \\
\hline Presbíteros & 1 & 14,29 & 6 & 18,75 & 1 & 100 & 4 & 57,14 & 12 & 25,53 \\
\hline Élites urbanas & 17 & 16,35 & 69 & 26,74 & 8 & 32 & 27 & 25,71 & 121 & 76,10 \\
\hline Sin especificar & 9 & 52,94 & 15 & 21,74 & 4 & 50 & 6 & 22,22 & 34 & 28,10 \\
\hline Burguesía administrativa & 6 & 35,29 & 38 & 55,07 & 3 & 37,50 & 7 & 25,93 & 54 & 44,63 \\
\hline Regidores & 3 & 50 & 14 & 36,84 & 2 & 66,67 & 1 & 14,29 & 20 & 37,04 \\
\hline Otros oficios concejiles y de & & & & & & & & & & \\
\hline administración real y señorial & 2 & 33,33 & 3 & 7,89 & 0 & 0 & 0 & 0 & 5 & 9,26 \\
\hline Letrados & 0 & 0 & 19 & 50 & 1 & 33,33 & 6 & 85,71 & 26 & 48,15 \\
\hline Otras profesiones liberales & 1 & 16,67 & 2 & 5,26 & 0 & 0 & 0 & 0 & 3 & 5,56 \\
\hline Burguesía económica & 2 & 11,76 & 16 & 23,19 & 1 & 12,50 & 14 & 51,85 & 33 & 27,27 \\
\hline Sin especificar & 1 & 50 & 6 & 37,50 & 0 & 0 & 8 & 57,14 & 15 & 45,45 \\
\hline Comerciantes & 1 & 50 & 8 & 50 & 1 & 100 & 3 & 21,43 & 13 & 39,39 \\
\hline Artesanos & 0 & 0 & 2 & 12,50 & 0 & 0 & 3 & 21,43 & 5 & 15,15 \\
\hline Élites rurales & 3 & 2,88 & 9 & 3,49 & 3 & 12 & 7 & 6,67 & 22 & 13,84 \\
\hline Sin especificar & 3 & 100 & 8 & 88,89 & 0 & 0 & 5 & 71,43 & 16 & 72,73 \\
\hline Labradores & 0 & 0 & 1 & 11,11 & 3 & 100 & 2 & 28,57 & 6 & 27,27 \\
\hline Se ignora & 27 & 25,96 & 73 & 28,29 & 7 & 28 & 52 & 49,52 & 159 & 32,32 \\
\hline Total & 104 & 100 & 258 & 100 & 25 & 100 & 105 & 100 & 492 & 100 \\
\hline
\end{tabular}

